\title{
Educar en tiempos de cambio climático para la resiliencia humana y la regeneración ambiental
}

\author{
Education in Times of Climate Change for Human Resilience and Environmental Regeneration
}

Educar em tempos de mudança climática para a resiliência humana e regeneração ambiental

José de Jesús Núñez-Rodríguez

Universidad de Santander

Grupo de Investigación FENIX

Cúcuta, Colombia

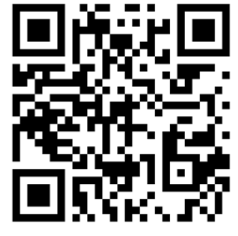

(iD) https://orcid.org/0000-0002-4120-0215

Julio César Carvajal-Rodríguez

Universidad de Santander

Grupo de Investigación FENIX

Cúcuta, Colombia

departamentodeeducacion@cucuta.udes.edu.co

iD https://orcid.org/0000-0003-4517-8817

Recibido • Received • Recebido: 21 / 07 / 2019

Corregido • Revised • Revisado: 22 / 03 / 2021

Aceptado • Accepted • Aprovado: 06 / 04 / 2021

\begin{abstract}
Resumen: En este artículo de reflexión se abordan la resiliencia humana y la regeneración ambiental en la formación de la población para la adaptación y mitigación de los efectos negativos del cambio climático. El objetivo es poner a disposición del personal docente las implicaciones de estos constructos en el comportamiento de las sociedades, en los escenarios del clima futuro, y la urgente necesidad de su valoración en las aulas de clase. El ensayo se ha construido a partir de la revisión acuciosa de bibliografía actualizada disponible en revistas indexadas y en documentos de organizaciones internacionales y su posterior contextualización pedagógica. El análisis realizado permite concluir que la escuela debe potenciar en sus estudiantes los procesos biológicos, cognitivos y emocionales relacionados con la resiliencia para persistir en ambientes inciertos, vulnerables y complejos, como efecto de la ocurrencia de eventos extremos de temperaturas (olas de calor y frio) y precipitaciones (sequías, inundaciones, huracanes). Asimismo, la educación debe formar a las futuras sociedades para emprender procesos de regeneración ambiental que reconstruyan los tejidos rotos de la naturaleza, como mecanismo para mitigar y resarcir los daños antrópicos. En estos escenarios pedagógicos la escuela es una institución de primer orden para formar a la ciudadanía que habitará un planeta con condiciones ambientales y recursos naturales aún desconocidos para el ser humano de hoy. La implementación de los constructos analizados amerita de políticas educativas, currículos escolares y personal docente formado para desarrollarlos desde sus aulas de clase
\end{abstract}

Palabras claves: Cambio climático; educación; regeneración ambiental; resiliencia ambiental. 
http://doi.org/10.15359/ree.25-2.30

http://www.una.ac.cr/educare

educare@una.ac.cr

\begin{abstract}
This article addresses human resilience and environmental regeneration in training the population to adapt and mitigate climate change's negative effects. The objective is to let teachers know about these constructs' implications in the behavior of societies in future climate scenarios and the urgent need for their assessment in the classroom. Constructing the essay implied conducting a thorough review of updated bibliography available in indexed journals and documents of international organizations and its subsequent pedagogical contextualization. The analysis allowed concluding that the school should strengthen, in its students, the biological, cognitive, and emotional processes related to resilience to endure uncertain, vulnerable, and complex environments as a result of the occurrence of extreme temperature events (heat and cold waves) and precipitation (droughts, floods, hurricanes). Likewise, education must train future societies to undertake environmental regeneration processes that rebuild the broken tissues of nature as a mechanism to mitigate and compensate for anthropic damages. In these pedagogical scenarios, the school is an institution of the first order to train citizens who will inhabit a planet with environmental conditions and natural resources still unknown to human beings today. Implementing the analyzed constructs requires educational policies, school curricula, and teachers trained to develop them in their classrooms.
\end{abstract}

Keywords: Climate change; education; environmental regeneration; environmental resilience.

Resumo: Este artigo de reflexão aborda a resiliência humana e a regeneração ambiental na formação da população, para a adaptação e mitigação dos efeitos negativos das alterações climáticas. $\mathrm{O}$ objetivo é disponibilizar aos professores as implicações destas construções no comportamento das sociedades, em cenários climáticos futuros, e a necessidade urgente da sua avaliação na sala de aula. O ensaio foi construído a partir da revisão completa da bibliografia atualizada disponível em revistas e documentos indexados de organizações internacionais e da sua subsequente contextualização pedagógica. A análise permite-nos concluir que a escola deve reforçar entre estudantes os processos biológicos, cognitivos e emocionais relacionados com a resiliência para persistir em ambientes incertos, vulneráveis e complexos, como resultado da ocorrência de eventos extremos de temperatura (ondas de calor e frio) e precipitação (secas, inundações, furacões). Do mesmo modo, a educação deve formar futuras sociedades para empreenderem processos de regeneração ambiental que reconstruam os tecidos quebrados da natureza, como um mecanismo para aliviar e compensar os danos antrópicos. Nestes cenários pedagógicos, a escola é uma instituição de primeira ordem para formar pessoas que habitarão um planeta com condições ambientais e recursos naturais ainda hoje desconhecidas para os seres humanos. A implementação das construções analisadas requer políticas educativas, currículos escolares e professores formados para os desenvolver nas suas salas de aula.

Palavras-chave: Mudança climática; educação; regeneração ambiental; resiliência ambiental.

\title{
Introducción
}

¿Está preparada la escuela para enseñar a la niñez y jóvenes a sobrevivir en un planeta más caliente? ¿El currículo educativo dispone de los dispositivos teórico-prácticos para incorporar la resiliencia humana ante los embates de los eventos climáticos extremos? ¿Se está enseñando a las nuevas generaciones a reconstruir los daños ambientales derivados por los modelos de

José de Jesús Núñez-Rodríguez y Julio César Carvajal-Rodríguez

Los artículos de la Revista Electrónica Educare del Centro de Investigación y Docencia en Educación de la Universidad Nacional, Costa Rica, se comparten bajo términos de la Licencia Creative Commons: Reconocimiento, № Comercial, Sin Obra Derivada 3.0 Costa Rica. Las autorizaciones adicionales a las aquí delimitadas se pueden obtener en el correo: educare@una.cr 
http://doi.org/10.15359/ree.25-2.30

desarrollo moderno? Estas interrogantes generan este ensayo como una necesaria reflexión sobre el papel de la escuela, y de educadores y educadoras, en la formación de las generaciones del cambio climático.

La ciencia climática ha venido aportando suficiente evidencia científica sobre las tendencias del calentamiento global por la acumulación de gases de efecto invernadero en la atmósfera (National Reseach Council, 2012) y diariamente la realidad mediática presenta preocupantes episodios generados por las olas de calor y frio, inundaciones, sequias, hambre, enfermedades, derretimiento de los casquetes polares, sismos, huracanes, extinción y migración de especies, entre ellas la del ser humano (Internal Displacement Monitoring Centre [IDMC], 2018). Es una realidad que muestra la fragilidad humana ante la fuerza destructiva de los fenómenos naturales.

Hasta ahora, la escuela, en su organización y funcionamiento, no ha asumido la gravedad de los escenarios que se hacen presentes por los efectos del cambio climático. Las acciones desarrolladas generalmente se enmarcan en actividades teóricas o prácticas, repetitivas y superficiales, referidas a la educación ambiental, dejando de lado las amenazas y riesgos que comienzan a sufrir grandes contingentes de seres humanos por las variaciones climáticas en sus territorios, ahora convertidos en vulnerables.

En este ensayo se desarrollan los conceptos de resiliencia humana y regeneración ambiental como nuevos constructos, útiles para educar a las generaciones del cambio climático, en un desafío por formar las capacidades de resiliencia biológica, cognitiva y emocional necesarias para soportar y adaptarse a altas temperaturas, migraciones humanas, cambios en la biodiversidad de los ecosistemas, eventos de lluvias y calores extremos, es decir, una transformación gradual en sus condiciones climáticas, naturales y productivas hasta ahora conocidas. El otro concepto analizado se relaciona con la regeneración ambiental y constituye una de las soluciones a la crisis ambiental que amerita la formación cabal de las nuevas generaciones para revertir los comportamientos de destrucción de los recursos de la biosfera y su urgente compromiso ético y existencial por la recuperación de los tejidos naturales, sociales y culturales que contribuirá, significativamente, con la mitigación de los impactos negativos del cambio climático.

En este desafío, la escuela ocupa un sitial central por ser una institución históricamente mediadora de los saberes al apoderarse y empoderar a sus estudiantes de teorías y buenas prácticas de las ciencias climáticas, pertinentes para formar a la ciudadanía a sobrevivir resilientemente en un planeta más caliente y en asumir la ineludible tarea de la regeneración ambiental de sus territorios.

\section{La resiliencia humana}

Partimos de la premisa que el homo sapiens a través de su historia evolutiva ha superado enormes obstáculos existenciales (Harari, 2015), y aunque estos han mermado la población, al mismo tiempo han permitido transformaciones y adaptaciones a nuevas condiciones ecológicas, 
http://doi.org/10.15359/ree.25-2.30

http://www.una.ac.cr/educare

educare@una.ac.cr

sociales y tecnológicas. Ejemplo de ello son las trágicas penurias vividas por hambrunas, epidemias, guerras, sequías e inundaciones durante distintos períodos de la historia humana, y superadas como producto de evoluciones y adaptaciones continuas; todo lo cual genera una gran capacidad de resiliencia socio ecológica ante situaciones adversas (Daza y Figueroa Casas, 2014). La resiliencia acompaña al ser humano durante todo el período de su vida, al convertirse en una capacidad amortiguadora, tipo buffer o tampón, que impulsa a la adaptación fisiológica, cognitiva, emotiva y organizacional a entornos cambiantes, situaciones imprevistas, adversas y muchas veces traumáticas de los estresores ambientales (García-Vesga y Domínguez-de la Ossa, 2013).

El concepto de resiliencia se origina del análisis de sistemas complejos en la ecología para describir la permanencia de los ecosistemas para mantenerse en una condición particular ante perturbaciones experimentadas en sus entornos. Hoy en día es pertinente para estudiar la capacidad de los sistemas de absorber las presiones externas, al mismo tiempo que se reorganizan internamente y cambian sin perder la función, estructura, identidad y retroalimentación (Seekell et al., 2017), propios de sistemas autopoieticos para reproducirse y mantenerse por sí mismos en diferentes estados de equilibrios dinámicos (Maturana, 1995) y en variados espacios y escalas temporales (Downes et al., 2013).

Esa misma capacidad resiliente es inherente a la recuperación ecológica dentro de la cual los organismos vivos, desde los niveles inferiores hasta los más evolucionados, responden favorablemente a estímulos de ambientes cambiantes y adversos trasladando sus equilibrios ecológicos (homeostasis) en un período de tiempo suficiente para la recolonización, o invasión posterior, a una catástrofe ecológica (de la Vega y Schilman, 2015) a nuevas zonas de desarrollo; proceso que deja en el camino a especies con poca capacidad de adaptación y privilegia a aquellas idóneas de prosperar fuera de sus dominios básicos de supervivencia (Darwin, 1859).

Por consiguiente, en un escenario de cambio climático extremo, las modificaciones genéticas y fenotípicas sucesivas de adaptación y acomodación de las especies a nuevas condiciones medioambientales generarán transformaciones diferenciadoras, a lo que hoy conocemos de la biodiversidad de nuestros ecosistemas, pero seguramente tendremos reservas bióticas para el disfrute y satisfacción de las necesidades humanas, a menos que, de continuar nuestra conducta como especie suicida (Valledor de Lozoya, 1999), terminemos acabando con el planeta, o que hayamos ya entrado en la temida fase de viaje inercial, sin retorno, por la superación de las condiciones de autocontrol de la biosfera previstos en la COP21 (Intergovernmental Panel on Climate Change [IPCC], 2019).

Quien educa en tiempos de cambio climático debe cultivar su propia resiliencia y estudiar rigurosamente la resiliencia y sostenibilidad de las poblaciones humanas y ecológicas a largo plazo (Seekell et al., 2017), para comprender las transformaciones por ocurrir en los escenarios del clima del futuro. Su acción debe ser mediadora para coadyuvar a la resiliencia de los núcleos humanos en su proceso de adaptación a nuevas zonas de vida, entendiendo que los incrementos 
http://doi.org/10.15359/ree.25-2.30

de temperaturas y las variaciones de la precipitación presionarán a los seres humanos a movilizaciones territoriales internas y externas (Organización Internacional de Migraciones [OIM] 2014), lucha por los recursos disponibles, cambios en sus sistemas productivos y enormes niveles de estrés fisiológico (Wilhelmi y Hayden, 2010). Lo anterior requiere la formación de nuevos seres humanos con capacidades integrales para desarrollar las resiliencias biológicas (buenas prácticas para la adaptación y mitigación del cambio climático), cognitivas (saber de adaptación a ambientes cambiantes) y emocionales (manejo del comportamiento en ambientes alterados), para sobrevivir en escenarios con incrementos de temperaturas hasta de $4{ }^{\circ} \mathrm{C}$ (Kammen, 2013) en las próximas décadas.

Una escuela resiliente amerita la adaptación de la educación al clima futuro, es decir, se debe repensar la escuela y a sus actores para formarles, prospectivamente, en nuevos equilibrios térmicos, ecosistemas cambiantes y continuas migraciones bióticas (seres humanos, animales y plantas); factores todos de naturaleza exógena que, indudablemente, impulsarán nuevas formas de organización escolar (estructuras horizontales y en redes), calendarios escolares adecuados a los calendarios climáticos (escuelas adaptadas a las contingencias climáticas particulares en sus territorios), atención de las poblaciones migrantes climáticas (educación intercultural), uso de recursos tecnológicos (teletrabajo, educación a distancia y virtual) y buenas prácticas de mitigación y adaptación de la escuela al cambio climático (diseños arquitectónicos climáticamente inteligentes, uso de energías alternativas, arborización de los espacios escolares, climatización de los ambientes escolares) y educación de la comunidad escolar ante la ocurrencia de fenómenos climáticos extremos (primeros auxilios, alertas tempranas, ayuda humanitaria, logística, atención psicosocial de víctimas)

\section{La regeneración ambiental}

La regeneración es un concepto que emerge del campo de la medicina regenerativa (Smith y X Ma, 2010) y tiene como tarea cosechar o crear tejidos para trasplantes que permitan remplazar los tejidos o células dañadas. En el campo del conocimiento ambiental es un constructo importante pertinente para reconstruir los tejidos destruidos históricamente en los ecosistemas mediante un cambio de paradigma del desarrollo, y de posturas del ser humano frente a la naturaleza, visto dentro de este marco como un desarrollo regenerativo.

La génesis del desarrollo regenerativo se ubica en los años noventa del siglo pasado con Lyle (1994, citado por Balboa y Domínguez, 2014), quien plantea que "cualquier sistema, partiendo de la agricultura, se puede organizar de forma regenerativa, emulando el funcionamiento de los ecosistemas, donde los productos se [crean] e interaccionan [naturalmente] sin producir residuos" (p. 83), y los daños o anomalías son curados por continuas regeneraciones de los organismos bióticos que forman parte del sistema en sus procesos continuos de evolución y adaptación autopoiética (Maturana y Varela, 2009). 
http://doi.org/10.15359/ree.25-2.30

http://www.una.ac.cr/educare

educare@una.ac.cr

Su aplicación en las ciencias sociales es pertinente por la urgente prioridad de la educación de fortalecer una cultura de la vida, desde el aula de clase, al formar agentes activos que puedan regenerar los tejidos ambientales, sociales y culturales direccionados a reconciliarse con la Pachamama, al asumir un mayor protagonismo en los procesos regenerativos del corpus planetario, lo que significa que el reto de una educación no sería otro que generar nuevas narrativas a incorporarlas en los currículos, y volver a lo que la filosofía naturalista griega planteó como una mirada contemplativa a la naturaleza, o una naturaleza sin perturbaciones, es nuestra mejor fuente para comprender cómo funcionan los procesos naturales.

Frente a los enormes desafíos que plantea el cambio climático se encuentra la protección y conservación, en su estado natural, de las áreas vitales para el equilibrio ambiental; tarea en la que la educación debe reconstruir y revalorizar los imaginarios culturales locales, dándoles una nueva resignificación para construir un ecosistema humano que incorpore, respetuosamente, los deseos y las necesidades humanas en los patrones de la naturaleza, en los flujos de energía y de materiales, y en los procesos de cambio medioambiental que contribuyan significativamente a minimizar la incertidumbre climática, potenciar las resiliencias ambientales y humanas $y$, al mismo tiempo, ir zurciendo las heridas causadas por siglos de destrucción de los ecosistemas.

En este sentido, regenerar los tejidos naturales devastados o debilitados por las acciones antrópicas significa plena conciencia de cambiar el paradigma del uso agotador de los recursos naturales de la biosfera para alimentar el consumo, la vanidad de la población, por un modelo centrado en el desarrollo regenerativo de la biosfera para recomponer los cursos naturales de la vida, hasta alcanzar niveles de sostenibilidad y viabilidad del proyecto humano en la tierra.

Las universidades, y la educación en general, deben generar narrativas innovadoras que apalanquen una nueva sostenibilidad (Sonetti et al., 2019) al formar a las nuevas generaciones humanas en competencias cognitivas (reconstrucción ambiental), axiológicas (valores, actitudes y comportamientos hacia la consolidación de sociedades regenerativas), del saber hacer (habilidades para la reconstrucción ambiental) y del convivir (disfrute armónico del medio ambiente), en la que el personal docente y el estudiantado sean actores activos que participen en la gobernanza voluntaria de las cuestiones de la sostenibilidad, como componentes claves en la corregulación de las relaciones de la sociedad con su entorno ambiental, tal como lo prevé las Naciones Unidas en la Agenda 2030 para el Desarrollo Sostenible (D'Amato et al., 2019).

En definitiva, a la educación corresponde impactar sobre la escuela y la familia en la tarea de empoderar la regeneración ambiental -y cultural- de los territorios, para producir los bienes y servicios necesarios mediante el uso armónico y equilibrado de los recursos ecosistémicos que permitan la construcción de sinergias sostenibles entre los componentes de las comunidades vivas. Es interesante resaltar que las interacciones familiares dan forma al paisaje rural-urbano y estas, a su vez, tienen una relación con motivaciones e imaginarios que lo impactan positiva o negativamente (de Graa, 2019), generando, como residuos, diferentes perturbaciones, pérdidas 
http://doi.org/10.15359/ree.25-2.30

en diversidad e incrementos en la fragmentación del hábitat al afectar las características funcionales de su entorno.

La educación tiene el desafío de fortalecer lo social, como un vínculo necesario para la vida comunitaria, donde se compartan conocimientos, experiencias, valores y tradiciones que den significado e identidad a estos términos; lo cultural, al reconstruir y revalorizar los saberes históricos de las comunidades para la consolidación de las cosmovisiones e imaginarios que sientan las bases de las esencias raigales del ser humano y; lo ambiental, como el soporte de la vida de las especies y garantía del flujo de energía que garantiza la sostenibilidad y el equilibrio térmico de la biosfera, especialmente en estos momentos de altísima incertidumbre climática.

En términos contextuales, los currículos escolares deben estar centrados en la regeneración de la biosfera para incorporar en sus estudiantes saberes, sentires y haceres que cultiven la reconstrucción y recuperación ambiental de sus entornos. Esto incluye el estudio histórico de sus comunidades, saberes locales, características de sus ecosistemas, procesos productivos locales, impactos de las intervenciones humanas, zonas vulnerables y buenas prácticas de regeneración ambiental. Su implementación, por lo tanto, requiere de políticas educativas, currículos escolares y personal docente formado para impulsar un desarrollo regenerativo desde las escuelas.

\section{Conclusiones y recomendaciones}

La resiliencia es un constructo esencial en la prospectiva del cambio climático. Los cambios graduales del comportamiento térmico en el escenario de los próximos siglos permiten vislumbrar enormes presiones sobre los seres humanos al generarse transformaciones significativas en la biodiversidad de los ecosistemas, en los patrones de lluvias-temperaturas, ocurrencia de fenómenos atmosféricos extremos, nuevas enfermedades y plagas, y continuas migraciones climáticas de la población. La escuela debe educar al estudiantado para potenciar las resiliencias biológicas, cognitivas y emocionales para vivir, producir y trascender en un planeta más caliente, más complejo y más incierto.

La regeneración ambiental es un concepto que está impulsando un nuevo modelo de desarrollo, el desarrollo regenerativo, basado en una estrategia por recuperar los ecosistemas afectados por las acciones antrópicas en los territorios. El papel de la escuela es central en la formación de sus estudiantes para regenerar el tejido ambiental y cultural de sus comunidades, para ello requiere de políticas, currículos y personal docente consciente y formado para implementar el desarrollo regenerativo desde sus aulas de clase.

La resiliencia humana y la regeneración ambiental son dos constructos, entre muchos, útiles para formar a la sociedad a sobrevivir en un planeta más caliente, y perturbado en sus procesos de equilibrio natural, y para emprender las acciones necesarias de regeneración ambiental que recupere los tejidos de la biosfera destruidos por las acciones entrópicas de los modelos de desarrollo implementados. 
http://doi.org/10.15359/ree.25-2.30

http://www.una.ac.cr/educare

educare@una.ac.cr

Derivado de las reflexiones de los autores de este ensayo es recomendable profundizar sobre la aplicación pedagógica de los constructos en discusión, la formulación de políticas educativas, su implementación en los sistemas de organización escolar, en los currículos escolares, en las prácticas pedagógicas de docentes y en los proyectos educativos institucionales y de aula de los diferentes niveles educativos.

\section{Declaración de Material complementario}

Este artículo tiene disponible, como material complementario:

-La versión preprint del artículo en https://doi.org/10.5281/zenodo.3923015

\section{Referencias}

Balboa, C. H. y Domínguez Somonte, M. (2014). Economía circular como marco para el ecodiseño: El modelo ECO-3, Informador Técnico, 78(1), 82-90. https://doi.org/10.23850/22565035.71

D'Amato, D., Korhonen, J. y Toppinen, A. (2019). Circular, green, and bio economy: How do companies in land-use intensive sectors align with sustainability concepts? Ecological Economics, 158, 116-133. https://doi.org/10.1016/j.ecolecon.2018.12.026

Darwin, C. (1859). El origen de las especies. Feedbooks. https://www.rebelion.org/docs/81666.pdf

Daza, S. J. y Figueroa Casas, A. (2014). Factores que determinan la resiliencia socio-ecológica para la alta montaña andina. Revista Ingenierías Universidad de Medellín, 13(25), 45-55. https://doi.org/10.22395/rium.v13n25a3

de Graa, E. A. (2019). Daily urban systems explained from the household perspective: An exploratory research on how the spatial interactions of the individual households shape the structure of daily urban systems. European Planning Studies, 27(1), 106-125. https:// doi.org/10.1080/09654313.2018.1524454

de la Vega, G. J. y Schilman, P. E. (2015). La importancia de la fisiología en la distribución geográfica de los insectos. Revista de la Sociedad Entomológica Argentina, 74(3-4), 101-108. https://ri.conicet.gov.ar/bitstream/handle/11336/19498/CONICET Digital Nro.23627. pdf? sequence $=1$ \&isAllowed $=y$

Downes, B.J., Miller, F., Barnett, J., Glaister, A.y Ellemor, H. (2013). How do weknow about resilience? An analysis of empirical research on resilience, and implications for interdisciplinary praxis. Environmental Research Letters, 8(1), 1-9. https://doi.org/10.1088/1748-9326/8/1/014041

García-Vesga, M. C. y Domínguez-de la Ossa, E. (2013). Desarrollo teórico de la resiliencia y su aplicación en situaciones adversas: Una revisión analítica, Revista Latinoamericana de Ciencias Sociales, Niñez y Juventud, 11(1), 63-77. https://www.redalyc.org/ pdf/773/77325885001.pdf 
http://doi.org/10.15359/ree.25-2.30

Harari, Y. N. (2015). Sapiens. De animales a dioses: Una breve historia de la humanidad. Debate.

Intergovernmental Panel on Climate Change. (2019). Special report global warming of $1,5^{\circ} \mathrm{C}-I P C C$. https://www.ipcc.ch/sr15/

Kammen, D. (2013). Complexity and interdisciplinary approaches to environmental research. Enviromental Research Letters 8(1), 1-3. https://doi.org/10.1088/1748-9326/8/1/010201

Maturana, H. y Varela, F. (2009). El árbol del conocimiento: Las bases biológicas del conocimiento humano (19. ${ }^{a}$ ed., 3. ${ }^{a}$ reimpresión). Editorial Universitaria. http://repositorio.uchile.cl/ handle/2250/119932

Maturana, H. (1995). La realidad: ¿Objetiva o construida? I. Fundamentos biológicos de la realidad. Anthropos. http://cc-catalogo.org/site/pdf/Maturana-Humberto.-La-Realidad-ObjetivaO-Construida.pdf

National Research Council (2012). Climate change. Evidence, impacts and choices. The National Academies Press. https://doi.org/10.17226/14673

Organización Internacional para las Migraciones. (2014). Migración, medio ambiente y cambio climático: Datos empíricos para la formulación de políticas (MECLEP). Glosario. https:// publications.iom.int/system/files/pdf/meclep glossary sp.pdf

Seekell, D., Carr, J., Dell'Angelo, J., D’Odorico, P., Fader, M., Gephart, J., Kummu, M., Magliocca, N., Porkka, M. y Puma, M. (2017). Resilience in the global food system. Environmental Research Letters, 12(2), 1-11. https://doi.org/10.1088/1748-9326/aa5730

Smith, I. O. y X Ma, P. (2010). Cell and biomolecule delivery for regenerative medicine. Science and Technology of Advanced Materials, 11(1). https://doi.org/10.1088/1468-6996/11/1/014102

Sonetti, G., Brown, M. y Naboni, E. (2019). About the triggering of UN sustainable development. Goals and regenerative sustainability in higher. Sustainability, 11(1), 1-17. https://doi. org/10.3390/su11010254

Internal Displacement Monitoring Centre. (2018). Global report on internal displacement. Autor. https://www.internal-displacement.org/global-report/grid2018/

Valledor de Lozoya, A. (1999). La especie suicida:El peligroso rumbo de la humanidad. Díaz de Santos.

Wilhelmi, O. V. y Hayden, M. H. (2010). Connecting people and place: A new framework for reducing urban vulnerability to extreme heat. Environ.mental Research Letters, 5(1), 1-8. https://doi.org/10.1088/1748-9326/5/1/014021 